\title{
SISTEM INFORMASI TAUKE SAWIT ONLINE UNTUK MENGHINDARI MONOPOLI HARGA DI DESA SENAMA NENEK
}

\author{
Sukri'), Salamun ${ }^{2)}$, Widdya Rahmalina ${ }^{3)}$ \\ Universitas Abdurrab \\ 1)Sukri@univrab.ac.id, ${ }^{2)}$ Salamun@univrab.ac.id, ${ }^{3)}$ Widdya.Rahmalina@univrab.ac.id
}

\begin{abstract}
ABSTRAK
Kelapa sawit merupakan komoditas yang dapat dijadikan sebagai alternatif untuk menciptakan lapangan tenaga kerja yang cukup besar baik usaha dagang, usaha jasa dan perindustrian. Dilihat dari luas daerah keseluruhan kelapa sawit di Desa Senama Nenek mencapai 4849.357, hal ini memberikan gambaran bahwa sektor perkebunan merupakan salah satu komoditas unggulan di Desa Senama Nenek. Pada setiap Kepala keluarga rata-rata memiliki kelapa sawit dengan luas 2-3 Ha. banyak pelaku bisnis melirik bisnis jual beli sawit yang disebut dengan "Tauke Sawit". Strategi Bisnis Tauke sawit rata-rata dengan cara pemberian pinjaman uang, pemberian pupuk, serta terkadang bagi hasil yang di kelolah oleh Tauke sawit sehingga para petani tidak bisa lagi berpindah ke Tauke yang lain atau sudah dimonopoli harganya. Agar terhindar dari monopoli harga maka perlu ada solusi dengan cara membuat sistem inforamsi online, pengguna dari sitem adalah tauke sawit, pengumpul buah (PB) sebagai pabrik sawit, petani, dan Pemerintahan Desa (PEMDES) sebagai pengawas bisnis. Hasil yang diharapkan adalah keterbukaan informasi dan terhindar dari jeratan monopoli harga dari tauke sawit.
\end{abstract}

Kata kunci: Sawit, Tauke, Monopoli, Penerima Buah

\begin{abstract}
Palm oil is a material that can be used as an alternative to create a large enough employment either trade business, service business and industry. Generating from the area of oil palm in Senama Nenek village reached 4849,357, this gives the definition that the agricultural sector is one of the leading commodities in Senama Nenek village. On each head of the family the average has an oil palm with an area of 2-3 Ha. many businesses are eyeing the business of buying and selling called "Tauke Sawit". Taukejualan Business Strategy average by way of cash, money, and also for the results in school by Tauke palm can no longer switch to another Tauke or already monopolized the price. In order to avoid the price monopoly, there needs to be a solution by creating an online information system, the user of the system is palm tree, fruit collector $(P B)$ as a palm mill, farmer, and village government (PEMDES) as business supervisor. Expected results are information disclosure and avoid the bondage of price monopoly from palm oil.
\end{abstract}

Key words: Palm, wholesale, Monopoly, Receiver Fruit 


\section{PENDAHULUAN}

Indonesia merupakan salah satu negara yang sedang berkembang dan maju, dapat terlihat pada saat ini seperti perkembangan kota-kota dan bangunannya juga begitu cepat perkembangnya. Pertanian di Indonesia mempunyai peran penting atas keseluruhan perekonomian nasional. Hal ini ditujukkan dengan banyaknya penduduk Indonesia lebih memilih jenis pekerjaannya di sektor pertanian seperti kelapa sawit. Begitu juga dengan Kabupaten Kampar propinsi Riau khususnya di Desa Senama Nenek, sebagian besar penduduknya masih berpenghasilan dari hasil pertanian atau perkebunan. Hasil pertanian yang mereka dapatkan masih bisa menunjang kehidupan mereka yang lebih baik lagi untuk memenuhi kebutuhan hidup setiap harinya. Salah satu sektor pertanian yang sangat berkembang pesat di Indonesia saat ini adalah sektor perkebunan kelapa sawit khususnya di Desa Senama Nenek sektor perkebunan merupakan sektor unggulan (leading sector) yang dapat meningkatkan kesejahteraan masyarakat.

Usaha perkebunan kelapa sawit merupakan komoditas yang dapat dijadikan sebagai alternatif untuk menciptakan lapangan tenaga kerja yang cukup besar baik usaha dagang, usaha jasa dan perindustrian. Pada Provinsi Riau khususnya daerah Kampar yang mencakup Desa Senama Nenek, untuk produksi tandan buah segar (TBS) ataupun CPO (crude palm oil) menempati urutan pertama yaitu 7.680.797 ton untuk TBS dan 1.273.944 ton untuk CPO. Selain dari produksi yang dihasilkan, berdasarkan studi pustaka yang dilakukan juga daerah kampar memiliki 35 Unit pabrik kepala sawit (PKS) dan jumlah ini termasuk PKS di Desa Senama Nenek (Syahza, 2012).

Menurut data statistik kabupaten Kampar (kamparkab.bps.go.id, 2017 ), dapat dilihat dari luas daerah keseluruhan kelapa sawit di Desa Senama Nenek mencapai 4849.357 Ha, hal ini memberikan gambaran bahwa sektor perkebunan merupakan salah satu komoditas unggulan di Desa Senama Nenek. Pada setiap Kepala keluarga rata-rata memiliki kelapa sawit dengan luas 2-3 Ha (Cepriadi, 2015).

Berdasarkan perkembangan petani sawit, banyak pelaku bisnis melirik bisnis jual beli sawit yang disebut dengan "Tauke Sawit". Tauke sawit husus yang berada di wilayah desa senama nenek lebih kurang ada 8 Usaha Tauke Sawit. Tauke sawit selalu menggunakan strategi untuk mengikat petani sawit dengan cara pemberian pinjaman uang, pemberian pupuk, serta terkadang bagi hasil yang di kelolah oleh Tauke sawit. Strategi ini bertujuan petani agar tidak menjual buah sawit ke Tauke sawit lainnya. Sehingga banyak petani sawit yang merasa di monopoli melalui tekanan harga dengan alasan menyesuikan harga dari Penerima Buah (PB). Peningkatan hasil beli Tauke dapat di lihat pada gambar 1, 2, dan 3.

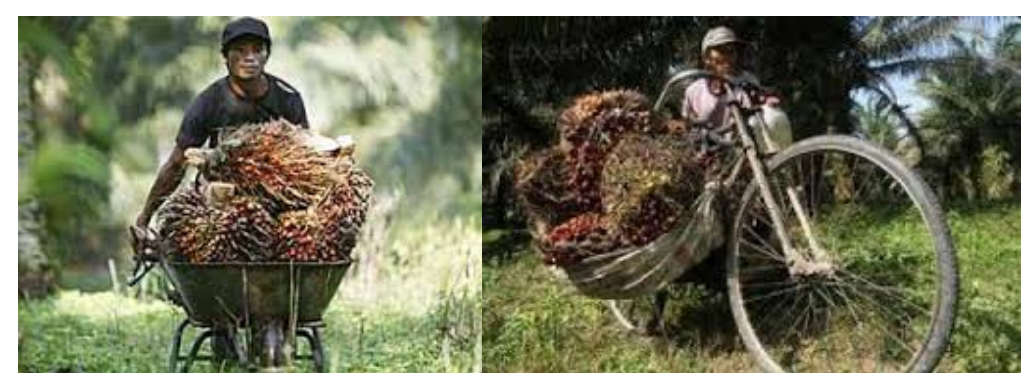
Gambar 1. Proses Petani Sawit Membawa Hasil Panen Ke Tempat Tauke Sawit Desa Senama Nenek 


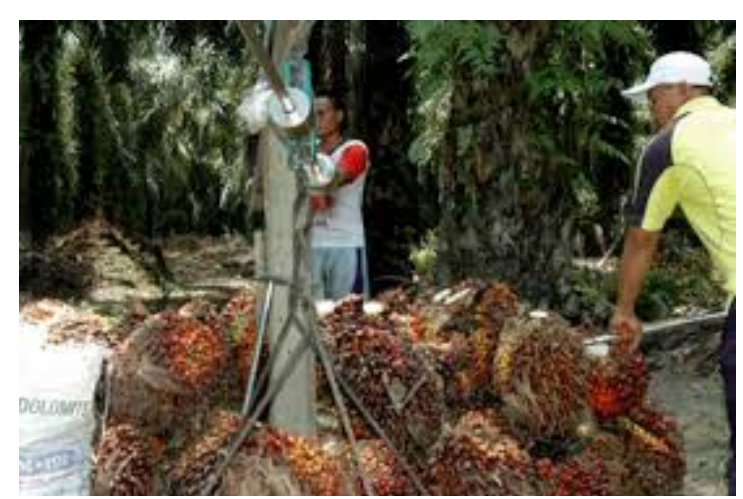

Gambar 2. Proses Penimbangan Sawit di Tempat Tauke Sawit

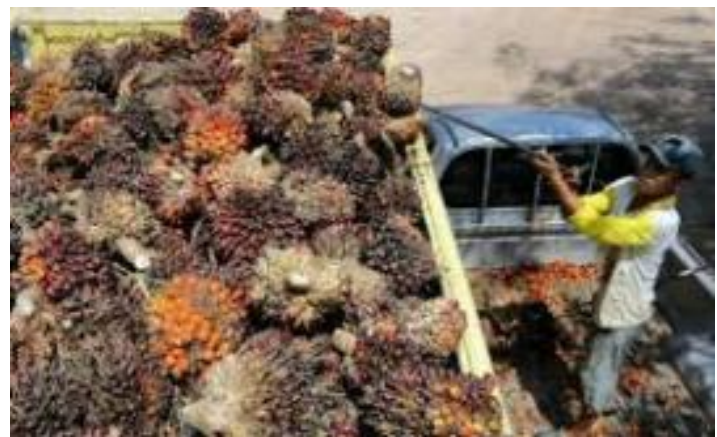

\section{Gambar 3. Proses Pengiriman Sawit Ke Tempat PKS dengam Menggunakan Penerima Buah (PB)}

Dengan adanya monopoli harga membuat para petani dirugikan dengan keterikatan hingga tidak jelas akhirnya. monopili ini terus menjamur bahakan hampir semua Tauke sawit di Desa Senama Nenek menerapkan sistem monopoli ini. Proses bisnis monopoli ini membuat para petani berbuat kecurangan untuk proses jual beli buah sawit dengan memiliki lebih dari satu Tauke sawit. Kecurangan tersebut membuat tidak keseimbangan tingkat kepercayaan antara petani dan Tauke sawit, serta antar Tauke sawit.

Berdasarkan analisis situasi tersebut muncul permasalahan-permasalahan Tauke dan Petani Sawit, yaitu: pertama Tauke sawit mengalami kesulitan untuk memberikan informasi kepada petani sawit mengenai harga dan proses jual beli sehingga petani tidak mendapatkan inforamsi yang salah. Kedua Bisnis Tauke sawit sudah mengarah stategi monopoli petani sawit, dengan adanya tekanan harga yang sangat tinggi. Ketiga Tidak transparannya harga mulai dari Penerima Buah (PB) hingga ke Tauke sawit sehingga harga di kalangan Tauke sawit sangat jauh perbedaannya. Keempat Kesulitan mengontrol Tauke sawit dengan Petani proses Langganan agar tidak terjadi Monopoli dan saling menguntungkan.

\section{TINJAUAN PUSTAKA}

\section{Kelapa Sawit}

Kelapa sawit sangat berkembang setiap harinya di tunjukkan dengan peningkatan hasil panaen masyarakat dan perubahan harga yang sangat tinggi, sehingga banyak dilirik para pebisnis untuk berlih kekelapa sawit. Banyaknya pebisnis juga membuat masyarakat bombing untuk menjual hasil panennya, karena beragam harga dan cara untuk mengikat petani. Menurut Sukri (2016), Pembuat keputusan sering kali dihadapkan pada kerumitan 
untuk memilih satu diantara banyak alternatif, masalah ini sering terjadi dikehidupan manusia sehari-hari.

\section{Tauke}

Berdasarakan kamus besar Indonesia Tauke adalah majika yang memilki usaha jual beli barang. Namun yang sering kita dengar adalah pembeli buah langsung dari masyarakat dengan terus menerus untuk mendapatkan penghasilan keuntungan secara maksimal.

\section{Petani Kelapa Sawit}

Menurut Kasus (2018), adapun industri kelapa sawit di Indonesia dibagi menjadi dua tipe kepemilikan (1) pabrik kelapa sawit besar (pemerintah atau swasta) yang mengontrol lahan sampai dengan sepuluh ribu hektar atau lebih, pembangunan kebun pabrik kelapa sawit dikenal dengan pembangunan kebun "inti". (2) Smallholder (petani kelapa sawit) adalah petani yang mengembangkan kebun kelapa sawit umumnya dibawah 10 hektar.

\section{BAHAN DAN METODE}

Kegiatan pengabdian masyarakat dilaksanakan pada Desa Senama Nenek Kecamatan Tapung Hulu Kabupaten Kampar. pelaksanakan dalam kurun waktu Maret 2018 hingga Mei 2018. Kegitan pengabdian masyarakat melibatkan tim pelaksanaan seluruhnya dari Program Studi Teknik Inforamtika Fakultas Teknik Universitas Abdurrab dan Mitra yang di jadikan objek pengabdian Tauke sawit Dasrel dan Tauke Sawit Hamik. Tahapan-tahapan kegiatan, prosedur sistematis dalam mengidentifikasi kebutuhan mitra yang dilaksanakan oleh pengabdi, yaitu :

1. Prosedur keja

Metode pelaksanaan kegiatan untuk mencari solusi dari permasalahan pemasaran Tauke dan Petani Sawit Desa Senama Nenek dilakukan dengan prosedur kerja yang mendukung realisasi pembuatan sistem informasi Tauke Sawit Online. Prosedur kerja dapat dilihat di Gambar 4

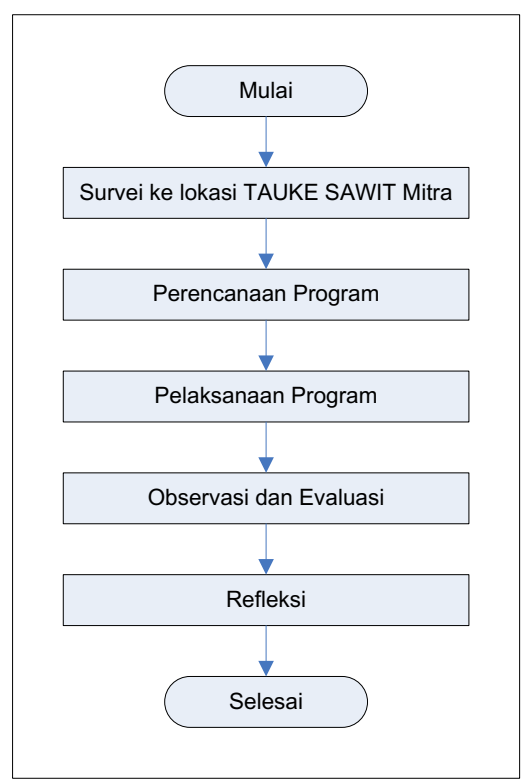

\section{Gambar 4. Prosedur pembuatan sistem informasi Tauke Sawit}

2. Metode pendekatan yang ditawarkan

Luaran yang dihasilkan berupa terciptanya sistem informasi yang terintegrasi antara Tauke-Tauke Sawit sebagai penjual dan pembeli berbasis teknologi informasi. Jenis luaran 
yang akan dihasilkan sesuai dengan rencana kegiatan baik dalam aspek produksi maupun manajemen usaha. Jenis luaran-luaran tersebut meliputi:

a. Perancangan dan pembuatan sistem aplikasi

Merancang dan membangun sistem informasi tauke sawit yang saling berintekrasi. Software yang digunakan meliputi:

1. PHP sebagai bahasa pemrograman yang digunakan untuk membangun aplikasi berbasis web

2. MySQL sebagai perangkat lunak untuk menampung data yang telah diinput.

Sedangkan Hardware yang digunakan pada pembuatan sistem aplikasi ini adalah Personal Computer

b. Pelatihan kepada Mitra

Memberi pelatihan kepada mitra Tauke sawit desa senama yang meliputi pelatihan operasional sistem aplikasi, pelatihan pengolahan data secara online, manajemen Sumber Data Manusia (admin sistem informasi dan owner/pemilik Tauke sawit), pelatihan sistem informasi kepada masyarakat, dan lain-lain.

c. Partisipasi Mitra Tauke Sawit

Partisipasi mitra ini diikuti dari awal, yaitu mitra aktif dari pertemuan awal antara mitra Tauke Sawit dengan tim program PKM dalam rangka studi lapangan untuk mendapatkan informasi-informasi yang menjadi permasalahan di Tauke Sawit Desa Senama Nenek, mengadakan diskusi dengan mitra untuk mendapatkan keinginan dari mitra dalam rangka meningkatkan keterbukaan informasi, serta proses bisnis yang sehat antar Tauke sawit. Jadi mitra ini dituntut aktif dari awal sampai dengan akhir kegiatan. Pada waktu pelatihan peran aktif mitra sangat penting, karena setelah program selesai maka semua kegiatan berada dibawah kendali mitra, oleh karena itu partisipasi mitra sangat penting. Arsitektur sistem informasi Tauke Sawit dapat dilihat di Gambar 5.

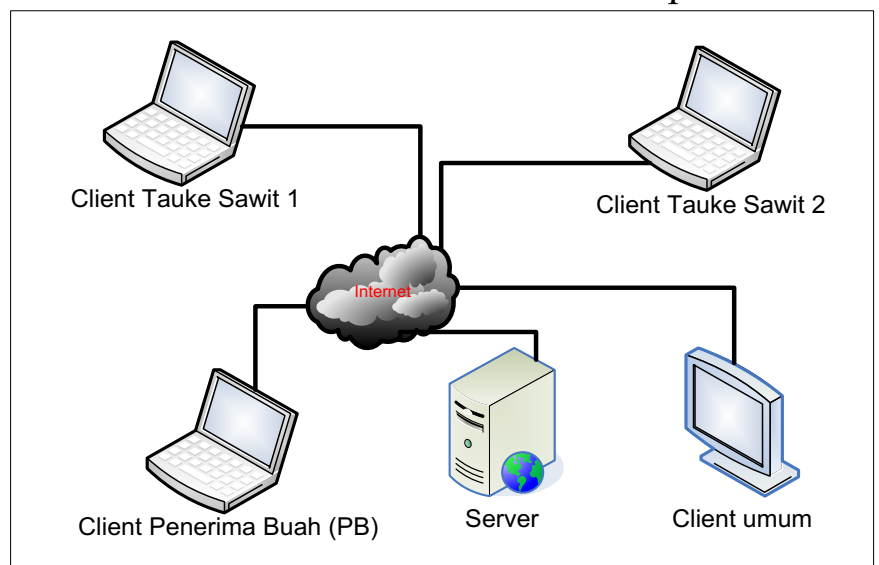

Gambar 5. Arsitektur Sistem Informasi Tauke Sawit

\section{HASIL DAN PEMBAHASAN}

\section{Survey lokasi}

Survei lokasi dua mitra (Tauke Hakim dan Tauke Dasrel) memiliki jarak lebih kurang lebih $94 \mathrm{KM}$ dengan waktu tempuh lebih kurang 2 jam dari Universitas Abdurrab. Survei dilaksanakan pada bulan April 2018 untuk melihat kondisi wilayah dan permasalahan masyarakat petani kelapa sawit dalam proses jual beli dan monopoli harga di Desa senama Nenek. Sambutan kami dari mitra sangat baik, dapat dilihat pada gamabar 6 . 


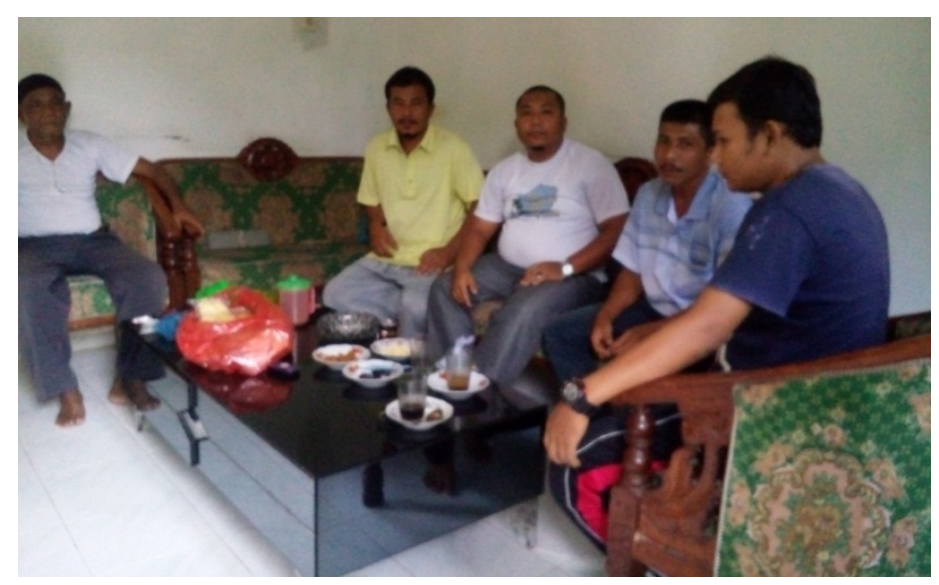

Gambar 6. Kondisi Ketemu dengan Mitra

Hasil dari diskusi dengan Tauke Sawit adalah sistem rantai pasok TBS terdapat beberapa pihak yang terlibat antara lain: (a) Agen pengumpul desa, (b) SP dan (c) PKS. Agen pengumpul di desa-desa sentra produksi membeli TBS petani kelapa sawit dengan harga yang sangat bervariasi. SP membeli TBS dari agen pengumpul desa dengan harga yang telah disepakati dengan petani. SP ini memiliki kuota pasokan pada PKS masing-masing dengan beberapa kewajiban yang harus dipenuhi. Pada rantai pasok TBS kelapa sawit terdiri dari 3 macam, yaitu:

a. Sistem Pasok I : Petani skala besar ke PKS

b. Sistem Pasok II : Petani skala kecil ke Satuan Pengumpul dan ke PKS

c. Sistem Pasok III : Petani kecil ke Agen Desa ke Satuan Pengumpul dan ke PKS

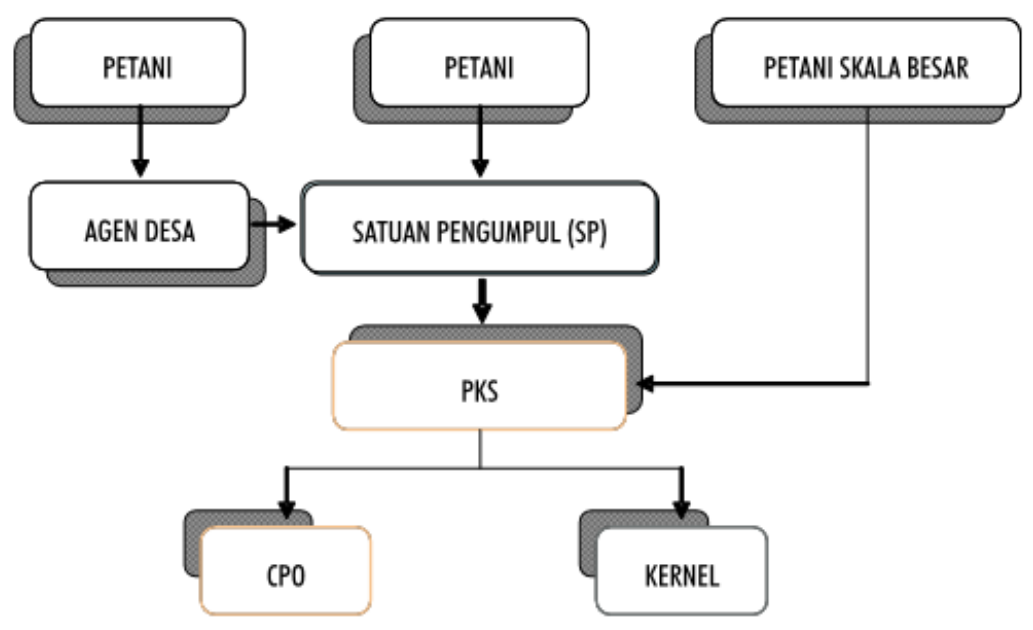

Gambar 7. Sistem Pasok

Dalam teori rantai pasok bahwa ukuran kinerja dan peran masing-masing pelaku ditentukan oleh empat hal, yakni: Persediaan, transportasi, fasilitas dan informasi. Kinerja persediaan pada pedagang pengumpul desa sangat tergantung pada ukuran produksi TBS yang dikelola melalui kelompok petani yang menjadi pemasok. Hal ini terukur dari volume pasokan dan kontinuitas produksi, pedagang pengumpul desa memiliki sistem transportasi mulai dari kendaraan langsir dan truk yang digunakan ke PKS. Fasilitas yang dimiliki oleh pedagang pengumpul desa dalam bentuk gudang penampungan dan perangkat pasokan seperti timbangan dan alat menentukan kematangan TBS. Pada umumnya pedagang pengumpul desa sebagai sistem pertama dalam rantai pasok TBS belum memiliki informasi yang transparan dari PKS, melainkan ditentukan oleh SP yang menjamin pasokan TBS 
tersebut. Dengan demikian kelemahan pedagang pengumpul desa adalah akses informasi volume dan harga penetapan TBS dari PKS tersebut. Berbeda halnya dengan kinerja petani skala besar yang telah memiliki akses langsung ke PKS, sehingga informasi volume dan harga TBS diterima langsung dari PKS tersebut. Petani skala besar ini juga telah melengkapi fasilitas pasokan dan sistem transportasi yang efektif. Oleh karena itu kinerja petani ini lebih baik dibandingkan dengan petani skala kecil dan pedagang pengumpul desa.

\section{Perencanaan Program}

Dari hasil penelitian yang dilakukan, maka dapat ditemukan data-data untuk membuat Sistem Informasi Tauke Sawit Online Untuk Menghindari Monopoli Harga Di Desa Senama Nenek Kecamatan Tapung Hulu Kabupaten Kampar Provinsi Riau. Dari hasil pengolahan data dapat diperoleh hak akses, yaitu :

a. Tauke Sawit

Merupakan hak akses untuk mendata pelanggan yang masuk, baik dari sisi manajemen peminjaman maupun dari segi data tonase

b. Petani atau Umum

Data inforamsi tenang harga penjualan dan tauke sawit yang memiliki harga pertauke

c. Pengepul Sawit (PB)

Memberikan informasi harga di pabrik setiap hari untuk dijadikan patokan oleh petani kelapa sawit.

\section{Pelaksanaan Program}

a. Rancangan Database

1. Tabel Transaksi

Data transaksi perlu terekap dengan baik agar tidak terjadi kesalapahaman antara tauke sawit dengan masyarakat yang mimiliki pinjaman dengan tauke. Sehingga perlu dibuat tabel rekapnya, dapat dilihat pada Gamabar 8.

\begin{tabular}{|c|c|c|c|c|c|}
\hline 1 & id & int(11) & No & None & AUTO_INCREMENT \\
\hline 2 & id_bayar & int(30) & No & None & \\
\hline 3 & id_toke & varchar(30) latin1_swedish_ci & No & None & \\
\hline 4 & tgl_bayar & varchar(50) latin1_swedish_ci & No & None & \\
\hline 5 & nominal & varchar(20) latin1_swedish_ci & No & None & \\
\hline 6 & pemb_ke & int(20) & No & None & \\
\hline 7 & sisa_bln & int(20) & No & None & \\
\hline 8 & sisa_htng & $\operatorname{int}(20)$ & No & None & \\
\hline
\end{tabular}

Gambar 8. Tabel Transaksi

2. Tabel Tauke

Setiap tauke sawit harus mendaftar terlebih dahulu menentukan status tauke dan untuk memberikan informasi kemasyarakat akan keterbukaan inforamsi harga dan legalitas dimasyarakat dan pemerintahan desa setempat. Hal ini dilakukan agar tauke bisa memberikan inforamsi secara terbuka dan tidak memonopoli harga secara sepik. Tabel untuk menyimpan data tauke dapat dilihat pada Gambar 9 dibawah ini. 


\begin{tabular}{|c|c|c|c|c|c|c|}
\hline 1 & id & $\operatorname{int}(11)$ & & No & None & AUTO_INCREMENT \\
\hline 2 & id_toke & varchar(20) & latin1_swedish_ci & No & None & \\
\hline 3 & tgl_daftar & varchar(50) & latin1_swedish_ci & No & None & \\
\hline 4 & nama_tk & $\operatorname{varchar}(300)$ & latin1_swedish_ci & No & None & \\
\hline 5 & hp & varchar(15) & latin1_swedish_ci & No & None & \\
\hline 6 & jk & varchar(30) & latin1_swedish_ci & No & None & \\
\hline 7 & desa & $\operatorname{varchar}(300)$ & latin1_swedish_ci & No & None & \\
\hline 8 & kec & $\operatorname{varchar}(300)$ & latin1_swedish_ci & No & None & \\
\hline 9 & kab & varchar(300) & latin1_swedish_ci & No & None & \\
\hline 10 & alamat & $\operatorname{varchar}(500)$ & latin1_swedish_ci & No & None & \\
\hline 11 & harga & varchar(20) & latin1_swedish_ci & No & None & \\
\hline 12 & status & varchar(50) & latin1_swedish_ci & No & None & \\
\hline
\end{tabular}

3. Tabel Pinjaman

\section{Gambar 9. Tabel Tauke}

Pendataan pinjaman dari masyarakat terhadap tauke sawit perlu dibuat agar tauke sawit mengetahui data masyarakat yang akan meminjam ke tauke, data tersebut dapat di jadikan acuan jumlah pinjaman dan lama atau banyak angsuran setipa angsuran serta jumlah angsuran. Untuk melihat data tersebut, maka dibuat tabel pinjaman dapat dilihat pada Gambar 10.

\begin{tabular}{|c|c|c|c|c|c|c|}
\hline 1 & id $\curvearrowright$ & $\operatorname{int}(11)$ & & No & None & AUTO_INCREMENT \\
\hline 2 & tgl_p & varchar(50) & latin1_swedish_ci & No & None & \\
\hline 3 & nama & $\operatorname{varchar}(300)$ & latin1_swedish_ci & No & None & \\
\hline 4 & hp & varchar(15) & latin1_swedish_ci & No & None & \\
\hline 5 & jk & varchar(30) & latin1_swedish_ci & No & None & \\
\hline 6 & alamat & $\operatorname{varchar}(500)$ & latin1_swedish_ci & No & None & \\
\hline 7 & aset & varchar(30) & latin1_swedish_ci & No & None & \\
\hline 8 & pendapatan & varchar(30) & latin1_swedish_ci & No & None & \\
\hline 9 & pinjaman & varchar(30) & latin1_swedish_ci & No & None & \\
\hline 10 & selisih & varchar(30) & latin1_swedish_ci & No & None & \\
\hline 11 & status & $\operatorname{varchar}(50)$ & latin1_swedish_ci & No & None & \\
\hline
\end{tabular}

4. Tabel Pabrik

Gambar 10. Pinjaman

Inforamsi harga sawit dari pabrik atau Penerima Buah (PB) sangat di butuhkan sebagai acuan masyarakat terhadap harga yang diberikan tauke ke masyarakat. Selisih harga pabrik atau penerima buah (PB) dengan tauke menentukan masyarakat memilih tauke yang akan di jadikan pinjaman dan penjualan buah sawit, sehingga masyarakat tidak merasa termonopoli harga dari tauke sawit.

$\begin{array}{lllll}1 & \text { id } & \text { int(11) } & \text { No None } & \text { AUTO_INCREMENT } \\ 2 & \text { tgl } & \operatorname{varchar(30)} & \text { latin1_swedish_ci } & \text { No None } \\ 3 & \text { nama_p } & \operatorname{varchar}(200) & \text { latin1_swedish_ci } & \text { No None } \\ 4 & \text { harga } & \text { varchar(20) } & \text { latin1_swedish_ci } & \text { No None }\end{array}$

5. Tabel Informasi

Gambar 11. Tabel Pabrik

Informasi secara umum se cara update perlu diberikan kepada masyarkat, har ini agar masyarakat mengetahui perkembangan sawit terbaru diluar wilayah desa, baik harga, 
penanaman, cara mengembangkan lahan sawit, dan lain sebagainya. Tabel informasi dapat dilihat pada Gambar 12.

\begin{tabular}{|c|c|c|c|c|c|c|}
\hline 1 & id $>$ & $\operatorname{int}(11)$ & & No & None & AUTO_INCREMENT \\
\hline 2 & tgl_post & $\operatorname{varchar}(50)$ & latin1_swedish_ci & No & None & \\
\hline 3 & uploader & - $\operatorname{varchar}(200)$ & latin1_swedish_ci & No & None & \\
\hline 4 & Judul & $\operatorname{varchar}(200)$ & latin1_swedish_ci & No & None & \\
\hline 5 & news & text & latin1_swedish_ci & No & None & \\
\hline
\end{tabular}

6. Tabel User Login

\section{Gambar 12. Tabel Informasi}

Agar semua hak akses bisa melakukan pengolahan data berdasarkan wilayah akses masing-masing user dan admin maka perlu dibuat penyimpanan data akse yang disebut dengan login. Tabel login dapat di lihat pada Gambar 13.

\begin{tabular}{|c|c|c|c|c|c|c|}
\hline 1 & id 2 & $\operatorname{int}(11)$ & & No & None & AUTO_INCREMENT \\
\hline 2 & tgl_daftar & $\operatorname{varchar}(30)$ & latin1_swedish_ci & No & None & \\
\hline 3 & nama & $\operatorname{varchar}(200)$ & latin1_swedish_ci & No & None & \\
\hline 4 & username & $\operatorname{varchar}(100)$ & latin1_swedish_ci & No & None & \\
\hline 5 & password & varchar(100) & latin1_swedish_ci & No & None & \\
\hline 6 & level & $\begin{array}{l}\text { enum('Non Aktif ' 'admin' 'ades', 'tauke', } \\
\text { 'pabri... }\end{array}$ & latin1_swedish_ci & No & None & \\
\hline
\end{tabular}

b. Rancangan Interface

Gambar 13. Tabel User Login

1. Tampilan depan

Halaman depan dari aplikasi berfungsi untuk menampilkan menu dan link yang akan diinginkan pengunjung atau user. Halam ini juga menampilkan inforamsi secara umum dan harga sawit dari pabrik atau pengumpul sawit (PB). Tampilan depan dapat dilihat pada Gambar 14.

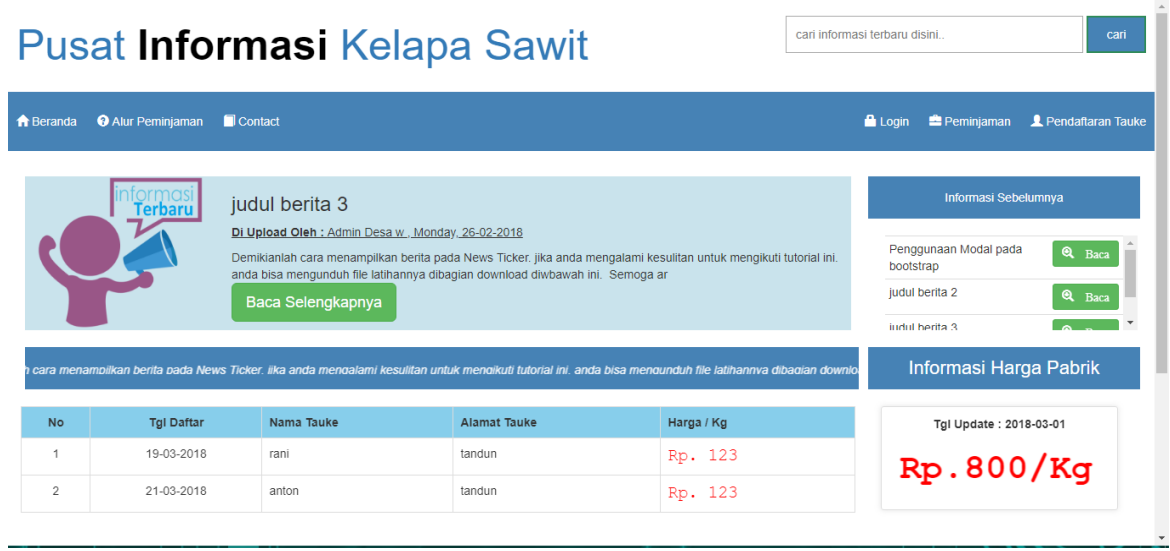

Gambar 14. Tampilan Depan

2. Tampilan Pendaftaran Tauke Kepada Desa Setempat

Halaman pengisian form pendaftaran berfungsi untuk halam pendaftaran untuk tauke yang ingin bergabung dalam bisnis sawit diwilayah desa senama nenek. Tampilan dapat di lihat pada Gambar 15. 


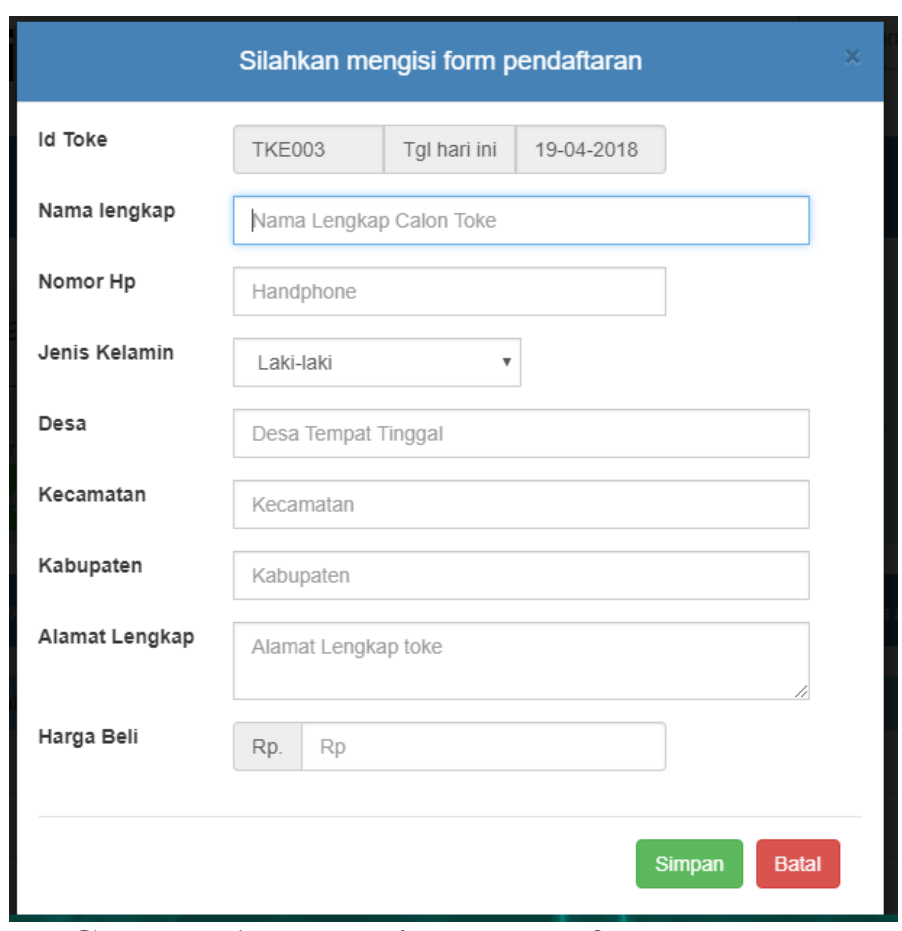

Gambar 15. Tampilan Pendaftaran Tauke

3. Tampilan Form Peminjaman Masyarakat Kepada Tauke

Masyarakat di desa kebanyakan selalu membutuhkan pinjaman ke tauke sawit, untuk itu sistem menyediakan tampilan untuk form pengisian agar masyarakat dengan tauke sawit tidak saling curiga dan juga dapat dijadikan sebagai keterbukaan inforamasi. Tampilan dapat dilihat pada Gambar 16.

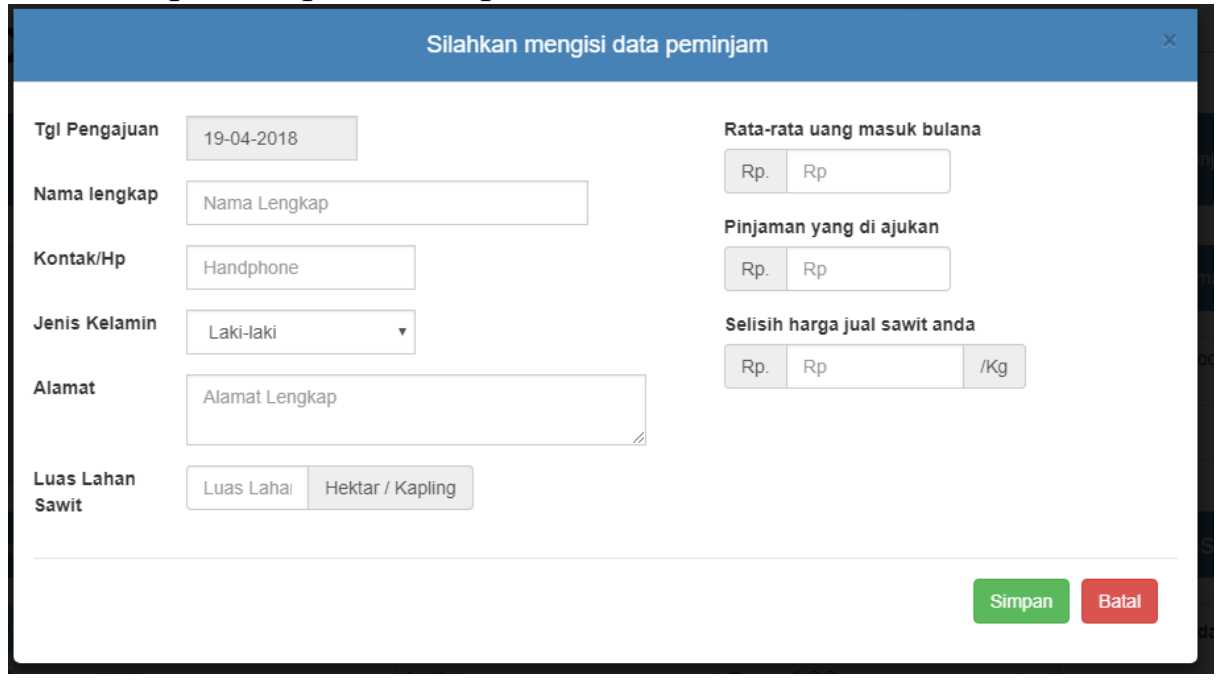

Gambar 16. Tampilan Pinjaman Masyarakat

4. Halaman Admin Untuk Admin Desa

Setelah melakukan login hak akses desa, maka dapat kita lihat tampilan admin dari desa pada Gambar 18, dan pada tampilan tersebut admin desa bisa melakukan pengolahan data pada tauke sawit, inforamsi harga, dan data masyarakat. 


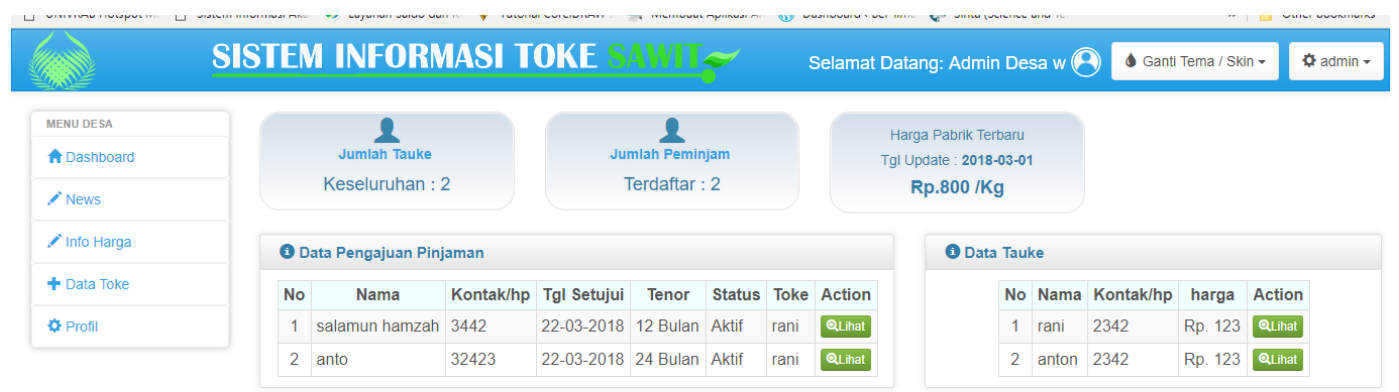

Gambar 18. Tampilan Admin Desa

5. Tampilan Admin Pabrik

Tampilan admin pabrik hanya untuk mengelola data harga yang ingin diberikan inforamsi kemasyarakat. Dapat dilihat pada Gambar 19.

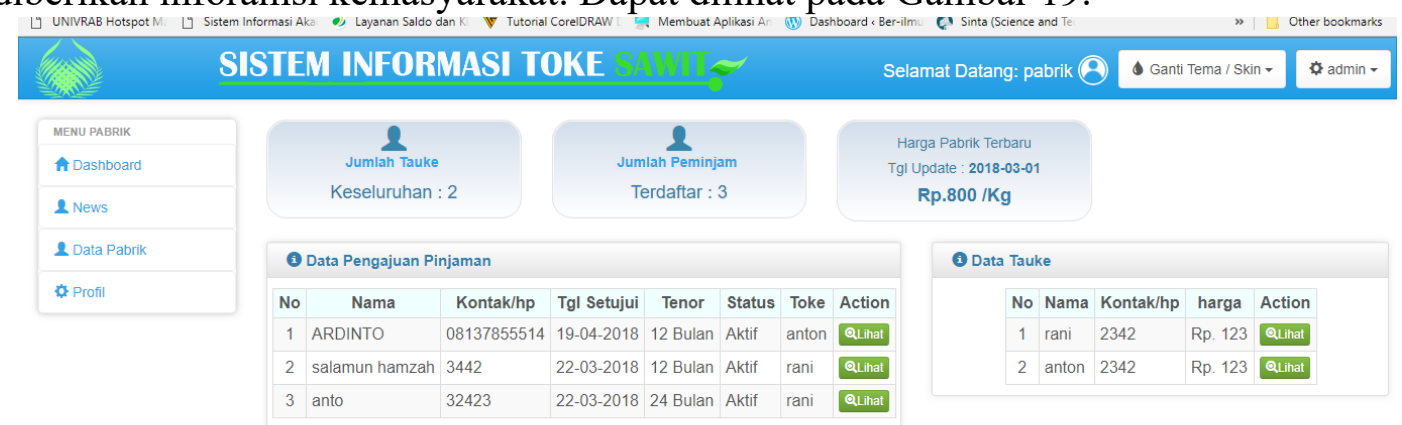

Gambar 19. Tampilan Admin Pabrik

6. Tampilan Admin Tauke

Data admin tauke dapat dikelola melalui form admin tauke yaitu data pinjaman dari masyrakat untuk di terima atau di tolak dengan kategori jumlah pinjaman dan kesepakatan selisih harga dengan pabrik sawit atau PB.

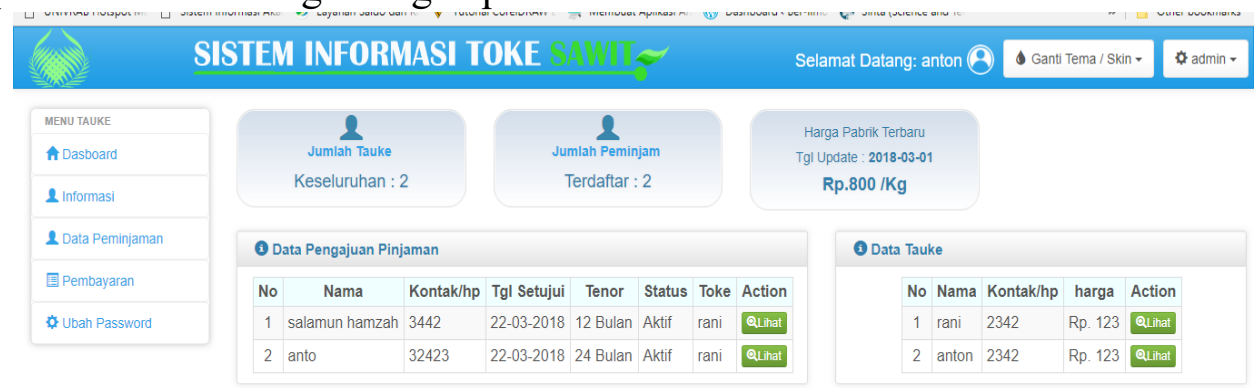

\section{Gambar 20. Tampilan Admin Tauke}

4. Observasi dan Evaluasi

Untuk melaukan observasi sitem sudah bisa diakses secara online disitus website sistawit.com.

\section{Refleksi}

Setelah aplikasi diselesaikan, tim pengabdian kemudian melakukan sosialisasi dan pelatihan terhadap aplikasi sistem informasi tauke sawit. Peserta untuk melakukan sosialisasi adalah tauke sawit, masyarakat atau petani, pihak pabrik atau PB, dan pihak pemerintah.

\section{KESIMPULAN}


Berdasarakan hasil dari kerjasama tim dalam melaksanakan kegiatan pengabdian kepada masyarakat dengan tema "Sistem Informasi Tauke Sawit Online Untuk Menghindari Monopoli Harga Di Desa Senama Nenek" selama lebih kurang 6 bulan tim telah bekerja dengan baik dan mampu memberikan kontribusi yang maksimal sesuai dengan perannya masing-masing. Output yang berhasil dicapai selama melakukan pengabdian masyarakat antara lain: sistem inforamsi tauke secara online, buku, dan edukasi penggunakan sistem terhadap masyarakat.

\section{DAFTAR PUSTAKA}

[5]. Http://kamparkab.bps.go.id, diakses 14 april 2017.

[6]. Cepriadi, kausar. 2015. Profil petani kelapa sawit pola swadaya di desa senama nenek kecamatan tapung, http://lib.unri.ac.id, diakses 14 april 2017.

[7]. Kasus, s., sinunukan, d. And sinunukan, k. (2018) 'strategi nafkah dan pemanfaatan relasi-relasi sosial households', 2(3), pp. 383-402.

[8]. Syahza, almasdi. 2012. Potensi pengembangan industri kelapa sawit. Hasil penelitian mp3ei tahun 2012.

[9]. Sukri (2016) 'sistem pendukung keputusan penentuan daerah tanaman kelapa sawit dengan metode promethee', rabit(jurnal teknologi dan sistem informasi univrab), 1(2), pp. 79-93. Available at: http://jurnal.univrab.ac.id/index.php/rabit/article/view/26. 